\title{
Potencialidades do Cinema de Fiç̧ão Científica em Contexto de Reclusão e o seu Impacto na Construção de Comunidades de Aprendizagem
}

Potencialidades del Cine de Ficción Científica en Contexto de Reclusión y su Impacto en la Construcción de Comunidades de Aprendizaje

The potencial of Science Fiction Cinema in a Prison Context and its Impact on the Construction of Learning Communities

\author{
José António Moreira \\ Departamento de Educação e Ensino a Distância \\ (Universidade Aberta) \\ https://orcid.org/0000-0003-0147-0592 \\ Portugal \\ Elsa Rodrigues \\ Instituto de Psicologia Cognitiva, Desenvolvimento Humano e Social \\ (Universidade Coimbra) \\ https://orcid.org/0000-0003-3088-820X \\ Portugal \\ - Artigo convidado - \\ Data de recepção: 27 de janeiro de 2019 \\ Data de publicação: 1 de julho de 2019 \\ Para citar este artigo: Moreira , J. A. y Rodrigues. E. (2019). Potencialidades do Cinema \\ de Ficção Científica em Contexto de Reclusão e o seu Impacto na Construção de Comunida- \\ des de Aprendizagem, Icono 14, 17 (2), 130-153. doi: 10.7195/ri14.v17i2.1353
}




\section{Resumo}

As potencialidades do cinema de ficção científica enquanto objeto e ferramenta de exploração pedagógica devem-se à riqueza do género que na linguagem cinematográfica, modelo narrativo e temas tratados, transcende os limites dos outros géneros, oferecendo possibilidades de exploração para diversas áreas disciplinares. Ao apresentar alternativas e extensões epistemologicamente possiveis da realidade oferece reconfigurações imaginadas da humanidade, cosmos, práticas científicas, instrumentos tecnológicos, tradições etnográficas, espaços físicos, organizações sociais, modelos económicos, ideologias, estruturas identitárias e até do espaço e tempo enquanto noções estruturantes da realidade. Com efeito, integrar um filme de ficção científica em contexto educativo pode ser uma estratégia muito adequada para revitalizar a experiência educacional, e é precisamente, a criação de cenários pedagógicos enriquecidos com a presença do cinema e da sua linguagem que pretendemos analisar, descrevendo o seu impacto na construção de uma comunidade de aprendizagem, a partir da análise qualitativa das perceções e narrativas de vinte estudantes a frequentar o Ensino Superior em ambiente de reclusão e tendo como referencial o modelo pedagógico desenvolvido por Moreira (2017). Os resultados revelam que a utilização do cinema de ficção científica, ancorado no modelo pedagógico para a desconstrução de imagens em movimento, pode ter efeitos muito positivos na criação e desenvolvimento de comunidades de aprendizagem em ambiente de reclusão.

Palavras chave: Cinema de ficção científica; Modelo pedagógico; Comunidade de aprendizagem; Reclusão; Educação nas prisões

\section{Resumen}

Las posibilidades del cine de ficción científica como objeto y herramienta pedagógica se derivan de la riqueza de un género que, por su lenguaje cinematográfico, su modelo narrativo y los temas que trata, trasciende los límites de otros géneros y permite explorar diferentes disciplinas. Al presentar alternativas y extensiones epistemológicas a la realidad, ofrece reconfiguraciones imaginadas de la humanidad, del cosmos, de las prácticas científicas, de los instrumentos tecnológicos, de las tradiciones etnográficas, de los espacios fisicos, de las organizaciones sociales, de los modelos económicos, de las ideologías, de las estructuras 
identitarias e incluso del espacio y del tiempo en cuanto nociones estructuradoras de la realidad. En efecto, utilizar una película de ficción en el proceso educativo puede ser una adecuada estrategia para revitalizar la experiencia formativa. Es precisamente la creación de escenarios pedagógicos enriquecidos con la presencia del cine y de su lenguaje lo que pretendemos analizar — describiendo su influencia en la construcción de una comunidad de aprendizaje- a partir del estudio cualitativo de las percepciones y narrativas de veinte estudiantes de enseñanza superior en el sistema penitenciario y tomando como referencia el modelo pedagógico desarrollado por Moreira (2017). Los resultados demuestran que el uso del cine de ficción científica anclado en el modelo pedagógico para la deconstrucción de imágenes en movimiento puede tener efectos muy positivos en la creación y el desarrollo de comunidades de aprendizaje dentro del sistema penitenciario.

Palabras clave: Cine de ficción científica; Modelo pedagógico; Comunidad de aprendizaje; Sistema penitenciario; Educación en las prisiones

\section{Abstract}

The potential of science fiction cinema as object of analysis and learning tool is due to the richness of the genre. In fact, using imagination as a critical tool, science fiction cinema projects the existential, epistemological, ontological and anthropological anxieties of the world we inhabit in other times and spaces, reaching a public that otherwise would hardly be mobilized for a critical analysis and offering possibilities of exploration for several disciplinary areas. Using 'what if' hypothesis, science fiction stimulates the viewer's critical thinking by presenting epistemologically possible reconfigurations of humanity, cosmos, scientific practices, technological tools, ethnographic traditions, physical spaces, social organizations, economic models, ideologies, identity structures and even space and time as ontological and epistemological notions. For those reasons, the use of science-fiction films in an educational context can be a very appropriate strategy to invigorate the educational experience, and it is precisely, the creation of pedagogical scenarios enriched with the presence of the cinema that we intend to analyse, describing its impact on the construction of a learning community. The study is based on the qualitative analysis of the perceptions and narratives of twenty students in confinement (an environment of imprisonment), having as reference the pedagogical model developed by 
Moreira (2017). The results show that the use of science fiction films cinema, anchored in the pedagogical model for the deconstruction of moving images, can have very positive effects on the creation and development of learning communities in reclusion environments.

Key Words: Science fiction cinema; Pedagogical model; Learning community; Reclusion; Prison education

\section{Introdução}

A educação é um direito universal e desempenha um papel crucial no desenvolvimento humano, ajudando o indivíduo a construir a sua personalidade e o seu carácter. Mesmo em situação de reclusão, e tendo em conta as Recomendações do Conselho da Europa referentes à Educação nas Prisões (1989) e as diretrizes do Instituto da Educação da UNESCO (1998) os cidadãos possuem os mesmos direitos no acesso à educação. Com efeito, a reclusão implica a perda de alguns direitos, mas estes não se devem estender à educação, na medida do possível, sobretudo, porque a educação e a formação, neste contexto, tende a assumir-se como um dispositivo promotor de reinserção social e de combate à reincidência. Por isso, e de acordo com o mesmo organismo, deve-se "desenvolver e aplicar programas educativos nas prisões, com a participação dos reclusos, a fim de satisfazer as suas necessidades e aspirações de aprendizagem e facilitar o trabalho nas prisões às organizações não governamentais, professores e outros organizadores de atividades educativas" (1998, p. 54).

Estudos já desenvolvidos neste século, como o estudo Educação nas Prisões realizado no Reino Unido, no início deste século, sublinha, também, a importância de encarar o ensino como uma parte integrante de um processo global de recuperação do indivíduo. Apesar de se afirmar, inequivocamente, a importância do ensino no combate à reincidência, no mesmo relatório salvaguarda-se a ideia que em matéria de reabilitação de indivíduos tem de existir uma ação concertada em diferentes vertentes da vida do ex-recluso. Aumentar as competências e as qualificações dos reclusos é importante, mas não é o suficiente para reduzir a reincidência, isolando outros fatores. 
Existem, pois, evidências empíricas que o ensino integrado nas diferentes valências que compõem o tratamento penitenciário é crucial para o processo reintegrador do indivíduo. E não apenas no que diz respeito à importância do ensino como forma de acesso ao mercado de trabalho, mas também no impacto das aquisições escolares e na transformação pessoal do indivíduo, aumentando a sua autoestima, o seu comportamento pró-ativo e a autonomia, a sua capacidade de resolver problemas, de comunicar, de colaborar, de trabalhar em grupo, valências fundamentais em qualquer projeto de reinserção social.

Foi, pois, com a intenção de promover o desenvolvimento de algumas destas competências, como a comunicação, a colaboração, ou a capacidade de resolver problemas que desenvolvemos um programa educativo num estabelecimento prisional, focado na Educação para a Cidadania, e assente na utilização do cinema de ficção científica, como principal recurso educativo. A opção por esta metodologia assente na utilização das tecnologias audiovisuais assume, claramente, a responsabilidade de desenvolver uma educação para e com a imagem, integrando o cinema nas atividades de aprendizagem, porque na realidade, como afirma Fresquet (2013) com o cinema como parceiro, a educação tende a inspirar-se provocando as práticas pedagógicas esquecidas da magia do que significa aprender.

Na realidade, o cinema de ficção científica encerra em si um imenso potencial educativo, no entanto este potencial depende muito do modelo e da estratégia pedagógica utilizada, do conhecimento da linguagem fílmica e da criatividade do professor.

A linguagem fílmica, mais do que uma semântica, exige uma pragmática, uma construção ativa de sentido com base em competências que assentam em vivências, mas também em conhecimentos, numa cultura mais ou menos partilhada que se assume ser transmitida pelo sistema educativo. Se isto é verdade para qualquer filme, sê-lo-á ainda mais para um filme de ficção científica. Em primeiro lugar porque o referente, não só está ausente como não existe. As realidades da ficção científica são mundos possíveis, realidades não existentes a que o cinema dá forma, obrigando muitas vezes a desenvolver a própria linguagem cinematográfica no sentido de dar solução técnica às exigências que a estranheza radical coloca, como aconteceu com os efeitos especiais e imagem digital. 
Considerando, pois, as potencialidades do cinema de ficção no desenvolvimento das competências atrás enunciadas desenvolvemos um programa de Educação para a Cidadania assente num modelo pedagógico centrado na "desconstrução" de imagens em movimento, com o objetivo de avaliar o seu impacto em dimensões como a capacidade de discutir e resolver problemas, ou a nível da capacidade de comunicar ou da trocar opiniões, a partir da análise qualitativa das suas perceções e narrativas.

Este é um modelo cujas linhas de força e princípios teóricos se alicerçam numa aprendizagem: Construtivista, Colaborativa e alicerçada em Comunidades de Investigação (Garrison \& Anderson, 2005) que estimule a reflexão e o discurso crítico, a responsabilidade individual e social e o espírito criativo; baseada na Interação, assumindo-se a interação como um princípio subjacente ao processo pedagógico, determinante não só para efeitos de motivação, de encorajamento e de confiança mútua, mas também de avaliação reguladora do processo de ensino-aprendizagem e de feedback; promotora da Multiliteracia entendendo-se este conceito como a necessidade de desenvolver nos estudantes novas competências de análise discursiva, a ponto de os capacitar a transmitirem e representarem o seu mundo através de modelos ou novos formatos multimodais; de Cariz Humanista, onde o estudante, assume um papel ativo, empenhando-se e comprometendo-se com o seu processo de aprendizagem e onde o professor assume o papel de moderador que acompanha, motiva, dialoga, fomentando e mediando uma interação humana positiva (Salmon, 2000).

Para além disso este modelo baseia-se na Teoria da Flexibilidade Cognitiva, desenvolvida por Rand Spiro e colaboradores (Spiro et al., 1987; Spiro et al., 1988), para solucionar dificuldades de transferência de conhecimentos para novas situações. É uma teoria que se centra em casos que são analisados ou desconstruídos segundo múltiplas perspetivas ou temas e que considera dois processos de aprendizagem: o processo de desconstrução e o processo de travessias temáticas.

Entre as principais vantagens deste modelo, estão a aplicação de uma teoria de aprendizagem que permite uma base pedagógica consistente, o desenvolvimento da flexibilidade cognitiva dos estudantes e o estímulo da prática de análise. Este 
é um modelo que exige uma participação ativa na aprendizagem, começando por proporcionar uma análise em profundidade através da desconstrução do objeto que lhe garante o aumento da flexibilidade cognitiva pelos vários exemplos que vê desconstruídos. Esta participação, naturalmente, exige reflexão, amadurecimento dos conhecimentos e flexibilidade cognitiva.

Em síntese, a nossa investigação pretende perspetivar possíveis cenários e designs alternativos de aprendizagem, estudando o efeito deste modelo na criação de comunidades de aprendizagem e avaliando o seu impacto no desenvolvimento de competências, como a resolução de problemas, a comunicação, a colaboração ou 0 espírito crítico.

\section{0 Cinema de Ficção Científica: Panorama e Po- tencialidades Pedagógicas}

Como referido na introdução deste texto, o cinema de ficção científica encerra em si um enorme potencial educativo, no entanto este potencial depende muito da estratégia pedagógica e metodológica utilizada e do conhecimento da linguagem fílmica que o professor possui.

Um dos aspetos mais importantes a explorar pelo professor prende-se com a experiência cinematográfica em si. Como os estudos fílmicos sublinham, a narrativa fílmica não é alvo de uma mera apropriação percetual, mas é um texto dinâmico que obriga o espectador a uma construção intelectual, descobrindo, extrapolando e organizando a informação de modo a dar-lhe sentido. 0 espectador atua a vários níveis: percebe, identifica, interpreta, formula hipóteses, preenche lacunas, constrói relações e vive sentimentos.

Na ficção científica esta construção intelectual ainda é mais relevante, porque as competências requeridas não são as da mera leitura literal das imagens presentificadas, mas, dado o tratamento oblíquo, metafórico, que é dado aos temas abordados, a ficção científica obriga à mobilização de mais competências interpretativas, ao mesmo tempo que expande a capacidade de imaginar a diferença e explorar possibilidades, obrigando, ainda, à construção do paradigma ausente, ou seja, o eixo 
de possibilidades entre o aqui e agora do espetador (o mundo zero) e o universo retratado no ecrã. E é, precisamente, no universo imaginado, retratado no ecrã que residem as maiores potencialidades pedagógicas da ficção científica.

Em termos científicos 'ficção científica' é um termo que traduz um encontro aparentemente improvável entre elementos fantasia e racionalidade, imaginação e realidade, ficção e ciência (Telotte, 2001). Mas a dimensão racional e científica é o elemento determinante, em primeiro lugar porque lhe vem do contexto em que nasce, existindo, claramente, uma relação direta com os contextos histórico-sociais que the deram origem.

A ficção científica nasce num contexto em que a única regra é a mudança constante. Num mundo assim, imaginar o futuro é uma forma de planificação histórica, de antecipação das mudanças possíveis e de preparação para elas. Nesta perspetiva, a ficção científica e a História partilham algumas características, nomeadamente a necessidade de se mover na linha do tempo e de criar um distanciamento temporal para compreender o presente.

Um dos autores que defende a existência de uma clara relação entre a ficção científica e a História é Edward James, argumentando que ambas obrigam a uma reconstituição mais ou menos ficcional do mundo real, à exploração de diversas possibilidades, recorrendo à especulação como ferramenta metódica. História e ficção científica partilham a mesma vontade de entender o tempo (passado ou futuro) e movem-se no campo das hipóteses (do que poderá ter sido ou do que poderá ser) (James, 1994).

Pode mesmo defender-se, como faz Roberts (2000), que a ficção científica não é profética, mas nostálgica. Assenta num fascínio pelo passado e não pelo futuro. Para este autor a ficção científica não nos projeta para além do presente, mas conta-nos histórias do passado, sendo por isso um modo historiográfico, uma forma de escrever simbolicamente sobre o que já foi (long long time ago), mesmo quando o cenário é o futuro longínquo. 
Na realidade, a ficção científica é sempre uma heterocronia, um tempo outro, um desdobramento da realidade, que se situa num horizonte de todos os tempos possíveis, o que é bem explorado em filmes como Terminator ou Interstellar, cada um apresentando infinitas possibilidades de exploração pedagógica.

Mas a antropologia, sociologia, psicologia e outras ciências mais centradas no ser humano também encontram na ficção científica um campo de exploração ilimitado. Isto porque a representação do outro, do estranho funciona, na ficção científica, como dispositivo que obriga a refletir sobre o que representa ser humano, sobre os modelos sociais, políticos e culturais e, de uma forma mais oblíqua e metafórica, sobre a nossa própria atitude em relação à diferença.

Seja para afirmar a sua supremacia, seja para mostrar as suas debilidades, o modelo de humano da ficção científica corresponde ao perfil dominante na cultura ocidental moderna: indivíduo, masculino, caucasiano, heterossexual e habitante do hemisfério norte. Cada filme pode ser interpretado pelo grau de diferenciação e desvio que o outro introduz em relação a este modelo de identidade, ele próprio problematizado pelo desenvolvimento da psicologia, dispersão de papéis sociais, globalização dos mercados de trabalho e virtualização da realidade.

0 próprio tempo e o espaço e a noção de realidade sofreram processos de compressão, distensão e fragmentação, impedindo a construção de noções estáveis e unívocas, num mundo em que os outros, os duplos, as sombras do self ocidental moderno, se assumem enquanto agentes de discurso e instâncias de poder e 0 próprio eu se dilui em identidades líquidas e multiformes. 0 radicalmente outro da ficção científica fornece um espelho a partir do qual o eu humano se pode refletir e compreender, percebendo que a sua natureza é problemática e é, também ela, heterogénea e artificial.

0 cinema de ficção científica acumula uma vasta galeria de alienígenas, antropomórficos, xenomórficos ou polimórficos, benévolos, malévolos ou indiferentes, individuais ou coletivos, livres ou determinados, próximos ou distantes da compreensão humana, em que o alien se constitui como ameaça ou como possibilidade de redenção para a espécie humana (Kuhn, 1990; 1999). 
Mas as narrativas que mais diretamente apontam para as questões ontológicas e antropológicas, para a determinação das fronteiras e do sentido daquilo que significa existir no mundo e ser humano, são aquelas em que a alteridade se constitui como desvio do próprio humano. Nestes casos, o outro descobre-se no interior do eu, por infeção, desvio ou mutação que provocam a ameaça ou destruição da integridade biológica, psicológica ou emocional.

As narrativas que mais diretamente se enquadram nesta classe são aquelas em que a alteridade se constrói por sobre-humanização ou por sub-humanização do humano. Em qualquer dos casos, trata-se de uma pós-humanidade que se cruza muitas vezes com a fantasia ou versões pouco credíveis da ciência, como acontece com os super-heróis ou os monstros de matriz humana, herdeiros de Drácula e de Frankenstein, que traduzem as ansiedades geradas pela transformação do humano, seja por mutação ou por engenharia genética. As ansiedades relativas às transgressões que a ciência pode operar no corpo passaram, nas últimas décadas, a estar mais ligadas à tecnologia, originando narrativas que implicam a ciborguização do humano (Haraway, 1991).

No entanto as preocupações científicas e biológicas permanecem, quer ao nível da recriação do corpo humano com a clonagem, quer na dimensão viral, potencialmente epidémica, explorada em filmes como The Island ou até Gattaca.

Mas se nos casos dos filmes anteriormente referidos é o estatuto ontológico do indivíduo que é questionado ou afirmado de uma forma denotativa, clara, noutros casos este sentido tem de ser inferido e a narrativa interpretada, não de forma literal, mas enquanto metáfora, de onde deriva muita da riqueza textual da ficção científica. A luta pelos direitos civis e a fragmentação da identidade pós-moderna obriga a procurar o outro que existe no interior da comunidade, a diferença social, política, sexual ou étnica.

Nessa perspetiva, poderá compreender-se Men in Black de Barry Sonnenfeld, como uma alegoria à imigração ilegal, Independence Day de Emmerich, como uma representação dos medos relativamente à homossexualidade, Predator de John McTiernan como tradução das ansiedades relativamente aos negros, e Species de Ronald Donaldson, como manifestação das inquietações geradas pela afirmação do feminino. 
Os fenómenos migratórios, terrestres ou intergalácticos, também podem ser abordados através da ficção científica. Até à década de 1980 eram frequentes as narrativas de imperialismo, implicando a noção de conquista e colonização espacial, mas nas décadas seguintes esta tendência foi-se desvanecendo até desaparecer, deslocando-se a ação dos filmes de ficção científica para um planeta Terra cada vez mais multicultural, que contém ou recebe diferença.

Mas, como já foi afirmado, a ficção científica reflete também sobre aquilo que nos define como humanos na relação com as máquinas. Atualmente, já não é a racionalidade, a capacidade de produzir conhecimento correto do ponto de vista lógico e gnosiológico, que define o ser humano. Essa passa a ser uma competência que se pode atribuir à tecnologia, ao não humano. A definição do homem pode, assim, deixar de ser feita por oposição ao animal e passar a fazer-se em relação ao computador, dando-se uma revalorização da emoção.

0 não humano já não é o que não pensa, mas o que, pensando, é incapaz de emoção ou sentimento. A tecnologia, criada para replicar os processos mentais humanos de modo preciso, frio e mecânico, passa a ser lugar do inumano.

As narrativas sobre o corpo tecnológico, seja robô, ciborgue ou androide, manifestam as crescentes ansiedades acerca da nossa própria natureza e uma espécie de medo evolucionário de que essas entidades tecnológicas pressagiem o nosso desaparecimento, que poderá ocorrer por destruição ou por assimilação do orgânico e do não orgânico (Featherstone \& Burrows, 1995).

A tecnologia pode, assim, ser concebida como alteridade, como não humano, como elemento opositor ou como lugar de fusão, de conciliação, de encontro do humano com uma outra dimensão da sua própria natureza. Em qualquer dos casos permite a reflexão em torno da antinomia humano/máquina, que envolve um posicionamento em relação aos outros binómios que lhe são adjacentes, como razão/ emoção, natural/artificial, criação/criatura, liberdade/determinismo e mecânico/ espontâneo. 
A questão da memória como núcleo identitário também é um subtema recorrente na ficção científica das últimas três décadas, tornando-se central para a abordagem da possibilidade de duplicação do ser humano, quer por via tecnológica, quer por via biológica. As memórias, enquanto registo da vivência no tempo e no espaço e enquanto mecanismo de autenticação do passado, tornam-se chave de acesso e centro de identidade do eu. A sua transformação, por implante ou por apagamento, constitui uma forma de manipulação da essência do indivíduo, tal como sugerido no filme Blade Runner, o que permite uma abordagem psicológica sobre a importância das narrativas na constituição do eu (Bukatman, 1997).

Foi, pois, baseado nestes pressupostos, nesta ideia de que os universos imaginados obrigam a criar reconfigurações sociais e culturais, levando a questões de ordem antropológica, sociológica, psicológica e filosófica, que decidimos desenvolver este programa educativo, com recurso a filmes de ficção científica e a um modelo pedagógico que permitisse, não só desconstruir a informação presente nos filmes, transformando-a em conhecimento, mas também desenvolver competências fundamentais para um cidadão ajustado aos enormes desafios do século 21.

\section{Metodologia}

A natureza da indagação levou-nos a considerar pertinente uma abordagem como a Design Based Research (DBR) que parte do conceito de design experiments. Esta metodologia de pesquisa em educação predispõe-se a realizar investigação rigorosa e reflexiva para testar e aperfeiçoar ambientes de aprendizagem inovadores (Wang \& Hannafin, 2005). Trata-se de uma metodologia que procura pesquisar problemas educativos em contextos reais de atuação pedagógica, com vista à resolução de problemas significativos e práticos, conciliando teoria e prática.

A nossa amostra foi constituída por um grupo de 20 estudantes reclusos a frequentar o Ensino Superior na Universidade Aberta, Portugal, tendo estes estudantes respondido no final do programa de formação a um inquérito por questionário. Para analisar os dados referentes ao estudo, recorremos a uma técnica de investigação capaz de codificar as declarações semi-livres e aparentemente desordenadas: a análise de conteúdo (Bardin, 1977; Vala, 1986). 
Esta análise obedeceu a uma lógica de funcionamento baseada na alternância de duas fases. Numa primeira fase foi realizada uma análise vertical de cada uma das respostas dos estudantes e na segunda procedemos a uma análise horizontal ou comparativa com recurso ao método da "análise comparativa constante" (Miles \& Huberman, 1994) com o intuito de identificar aspetos comuns e distintivos das representações e perceções dos sujeitos. Para o efeito apresentamos a informação proveniente das respostas, também, em esquema, com o objetivo de exemplificar a relevância de algumas das suas opiniões. Por último referir ainda que algumas das unidades de registo, codificadas com a sigla UR, pelo seu carácter avaliativo, foram sinalizadas com as expressões de Tendência Positiva (+), Tendência Negativa (-) e Hesitação/Indefinição (+/-).

Tendo em conta o âmbito e o objetivo do estudo bem como a análise documental de alguns normativos relevantes no contexto em estudo, inspirámo-nos no Community of Inquiry Survey Instrument (CoI) desenvolvido por Garrison e colaboradores (2000), posteriormente adaptado por Moreira e Almeida (2011) à população portuguesa, para construir o nosso instrumento. Assim, como podemos ver na Tabela 1, as três dimensões que constituem o CoI foram aquelas que definimos para o nosso instrumento. A primeira -Presença Cognitiva- representando a capacidade dos membros do grupo construírem significados através da comunicação dialógica, da reflexão sustentada e do discurso crítico; a segunda -Presença Social- representando a capacidade dos participantes se projetarem socialmente e emocionalmente através dos filmes visualizados; e a terceira -Presença Docente- representando a capacidade do docente definir a direção, o design, a facilitação da presença cognitiva e da presença social no sentido da realização dos resultados de aprendizagem.

\begin{tabular}{|c|l|l|}
\hline \multicolumn{1}{|c|}{ Elementos } & \multicolumn{1}{|c|}{ Categorias } & \multicolumn{1}{c|}{ Indicadores } \\
\hline \multirow{4}{*}{ Presença Cognitiva } & Evento desencadeador & Perceção de dúvida \\
\cline { 2 - 3 } & Exploração & Troca de Informação \\
\cline { 2 - 3 } & Integração & Ligação de ideias \\
\cline { 2 - 3 } & Resolução & Aplicação de novas ideias \\
\hline
\end{tabular}




\begin{tabular}{|l|l|l|}
\hline \multicolumn{1}{|c|}{ Elementos } & \multicolumn{1}{|c|}{ Categorias } & \multicolumn{1}{c|}{ Indicadores } \\
\hline \multirow{4}{*}{ Presença Social } & Expressão Afetiva & Emoção \\
\cline { 2 - 3 } & Comunicação Aberta & Livre expressão \\
\cline { 2 - 3 } & Coesão do Grupo & Incentivo à colaboração \\
\hline \multirow{3}{*}{$\begin{array}{l}\text { Presença de Ensino/ } \\
\text { Docente }\end{array}$} & Design \& Organização & $\begin{array}{l}\text { Definição/início dos tópicos de } \\
\text { discussão }\end{array}$ \\
\cline { 2 - 3 } & Facilitação & Partilha de significados pessoais \\
\cline { 2 - 3 } & Instrução Direta & Enfoque na discussão \\
\hline
\end{tabular}

Tabela 1: Codificação do modelo Community of Inquiry

Com base nestas categorias, definimos uma série de questões abertas que constituíram o corpo do inquérito.

\section{Resultados}

Como referimos anteriormente com este estudo pretende-se conhecer as representações dos estudantes reclusos relativamente ao impacto do modelo pedagógico apresentado e do cinema de ficção científica, a nível da criação e desenvolvimento de uma comunidade de aprendizagem, sobretudo em aspetos relacionados com as dinâmicas comunicacionais criadas no seio dessa comunidade.

Assim, na primeira categoria, Presença Cognitiva, referente à capacidade dos estudantes discutirem, resolverem problemas e integrarem novos conhecimentos, a classificação das unidades de registo repartiu-se pelas frequências de Presença (+) e Ausência (-). A primeira, Presença, foi aquela que recebeu a maioria das referências, dezanove registos, o que sugere que os estudantes consideram que a estratégia desenvolvida, incorporada no modelo pedagógico, permitiu a troca de informações, a ligação e a aplicação de novas ideias, ou seja, o desenvolvimento de um processo verdadeiramente promotor do pensamento crítico; a segunda, $\mathrm{Au}$ sência, com um registo, traduz a incapacidade do modelo e do cinema de ficção científica promover esse processo de pensamento crítico. 
- Esta estratégia pedagógica foi muito importante, pois deu-me a oportunidade de discutir vários temas, e com isso uma maior capacidade de discussão, e também adquirir novos conhecimentos. (UR05).

- Neste país e, principalmente, no ambiente prisional ter uma discussão "saudável", procurando resolver problemas e integrar novos conhecimentos ainda são conceitos novos, recém-nascidos da utopia dos doutores. Mas foi bom. (UR09).

-Admito que seja uma boa estratégia, mas não gostei particularmente, porque ter discussões com os outros é coisa que não me apetece... (UR10).

Figura 1: Presença Cognitiva (Fonte: Elaborado pelos autores)

Como podemos ver na primeira unidade de registo exemplificativa o estudante -ES5-, refere que a estratégia foi muito importante, porque lhe deu a oportunidade de refletir e discutir diferentes temas e de adquirir novos conhecimentos.

Por sua vez, o estudante -ES9-, como podemos ver na segunda unidade de registo (UR09) considera que foi muito interessante ter a possibilidade de ter discussões "saudáveis" num contexto, onde a troca, a partilha de ideias e a liberdade (de pensamento) é algo incomum, e que só foi possível devido à "utopia" dos professores orientadores deste programa de formação que romperam com a status quo estabelecido.

Também as opiniões dos estudante -ES02- e -ES14- destacam a relevância da estratégia, porque na realidade:

“(...) com o passar das sessões, houve cada vez mais capacidade de entender 0 grupo, de discutir e assimilar as opiniões de cada um e de as aproveitar para adquirir mais conhecimentos." (UR02).

“a estratégia permitiu alinhar vários pontos de vista da mesma realidade visualizada, à luz das experiências, vivências e conhecimentos de cada um dos participantes." (UR14). 
As perspetivas fornecidas pelo "orientador" do filme permitiu aos estudantes ter acesso a novos referenciais que lhes foram permitindo alinhar os diferentes pontos de vista e aceder a novas perspetivas acerca da realidade. Com efeito, como referem García Amilburu e Lenderos Cervantes, "a virtualidade educativa do cinema radica principalmente no poder que têm as analogias para despertar a mente humana para o conhecimento da realidade" (2011, p. 43).

Por sua vez os estudantes -ES6- e -E13- consideram que este modelo permitiu:

“(...) a integração de novos conhecimentos e possibilitou que cada um pudesse emitir as suas opiniões, aceitando as diferenças com uma postura aberta à aprendizagem (UR6).

“(...) uma exemplificação de algo que podemos discutir e com isso sem dúvida adquirimos conhecimentos. (UR13).

Esta abordagem e ação pedagógica do professor revela-se extremamente importante, porque permite que o estudante, e como referem estes indivíduos, tenha uma participação ativa no processo de aprendizagem, construindo o seu próprio conhecimento (Moreira \& Monteiro, 2010).

No entanto, nem todas as afirmações vão no sentido da construção desta comunidade de aprendizagem. Como podemos ver na terceira unidade de registo exemplificativa o estudante -E10- afirma que, apesar de considerar a estratégia boa, não gostou particularmente da metodologia, talvez porque prefira abordagens mais clássicas, mais próximas de uma pedagogia expositiva ou explicativa, o que sugere que devemos considerar não apenas uma visão fechada sobre uma pedagogia ou modelo pedagógico, mas considerar a pedagogia na sua dimensão plural.

Estes testemunhos são reveladores da intenção óbvia de criar um ambiente de aprendizagem centrado na desconstrução de recursos audiovisuais, cinema de ficção neste caso, que encorajasse os estudantes a dialogar com o professor e entre si; que os encorajasse a resolverem os problemas e perguntarem uns aos outros a solução; que os estimulasse a assumir responsabilidade de assumir posições; que estimulasse a discussão e que mantivesse a sua curiosidade. 
Relativamente à segunda categoria, Presença Social, também com vinte registos, a classificação das unidades de registo mostra um número muito elevado de perceções de tendência muito positiva (dezanove) o que indicia, claramente, que os estudantes, consideram que o modelo e a metodologia permitiu fortalecer os laços afetivos entre os elementos da turma, formando uma comunidade de aprendizagem sólida, onde os membros dessa comunidade se exprimiram livremente e onde foram incentivados a colaborar e a partilhar informação e conhecimentos, com autonomia, criatividade e de uma forma muito ativa.

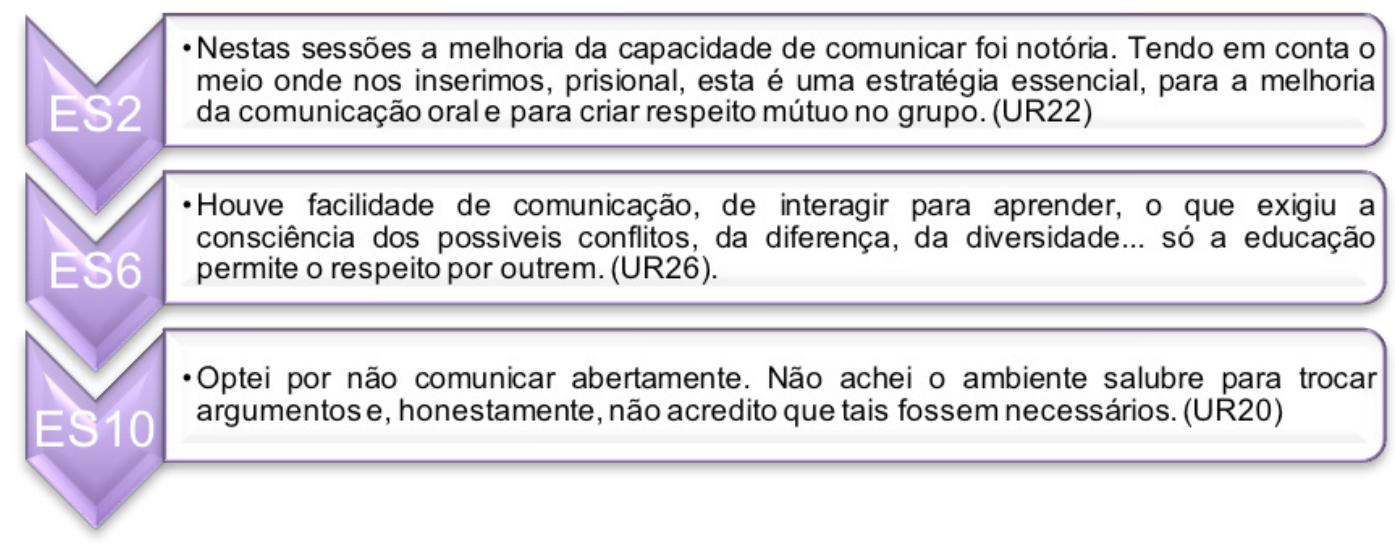

Figura 2: Presença Social (Fonte: Elaborado pelos autores)

Como podemos ver na primeira unidade de registo da Figura 2, o estudante ES2-, refere que a estratégia integrada no modelo permitiu melhor a capacidade de comunicar oralmente e criar a sensação de maior proximidade com os colegas devido ao respeito mútuo que existiu e que se foi fortalecendo ao longo do tempo. 0 estudante -ES01- sublinhou a mesma ideia, referindo também a ideia de:

ES11- “(...) comunicar abertamente, trocando argumentos com o grupo e com respeito pelas opiniões discutidas. (UR31)

Também, o estudante -ES6-, na segunda unidade de registo exemplificativa, sublinha a facilidade de comunicar neste espaço criado em ambiente prisional, da interação constante que criou oportunidades de aprendizagem e da tomada de 
consciência dos possíveis conflitos que podem emergir nestas discussões, resultado das diferenças culturais e da diversidade de pensamento dos diferentes elementos desta comunidade. E termina sublinhando que, na realidade, a educação é muito importante, sobretudo, na criação de valores como o respeito pela diferença de opiniões e de pensamento, por exemplo, como foi possível comprovar num filme como Alien 3, do realizador David Fincher, onde se discutiram, num cenário de universo imaginado, numa prisão espacial concebida pelo realizador, questões relacionadas com o sexismo ou a religião que "obrigaram" os participantes, também eles numa prisão (terrena e bem real) a criar novas reconfigurações sociais e culturais.

A maioria dos testemunhos recolhidos sublinha, pois, estas vantagens do ponto de vista do desenvolvimento de competências relacionadas, por exemplo, com a comunicação e a colaboração, com a discussão de ideias e de pontos de vista distintos, que implicou a "presença social" preconizada pelo modelo pedagógico e a desconstrução de ideias pré-concebidas.

ES13- “Participei por várias vezes, tirei dúvidas, por vezes fui esclarecido de algo que não estava a pensar bem. Pelo contrário em algumas intervenções sinto que despertei o entusiasmo dos participantes e motivei a discussão. (UR33)

ES14- “Este modelo estimulou a participação e partilha de opinião em grupo. Encontrei opiniões concordantes e discordantes do meu ponto de vista, mas sempre com uma argumentação válida. Foi na realidade muito estimulante e enriquecedor. (UR34)

De destacar, ainda que, como podemos ver na terceira unidade de registo exemplificativa, existe um estudante -ES10- que parece não se ter sentido confortável com a estratégia de implicação social, afirmando que o ambiente não seria o indicado para a discussão e que por isso decidiu não intervir nas discussões. Note-se, no entanto, que é esta uma posição isolada que parece estar relacionada com uma vontade do estudante não se querer expor publicamente perante o grupo, tendo optado por visualizar o filme e assistir passivamente às discussões geradas nas diferentes sessões.

Relativamente à terceira categoria, Presença Docente, também com vinte registos, a classificação das unidades de registo mostra uma concordância plena de opiniões o que indicia, claramente, que os estudantes, consideram que estes es- 
tudantes consideraram muito relevante o papel do docente, quer na organização do ambiente, quer, sobretudo na forma como foi direcionando as discussões ou incentivando as participações, promovendo desta forma um ambiente e um espaço verdadeiramente colaborativo com o apoio do cinema de ficção científica.

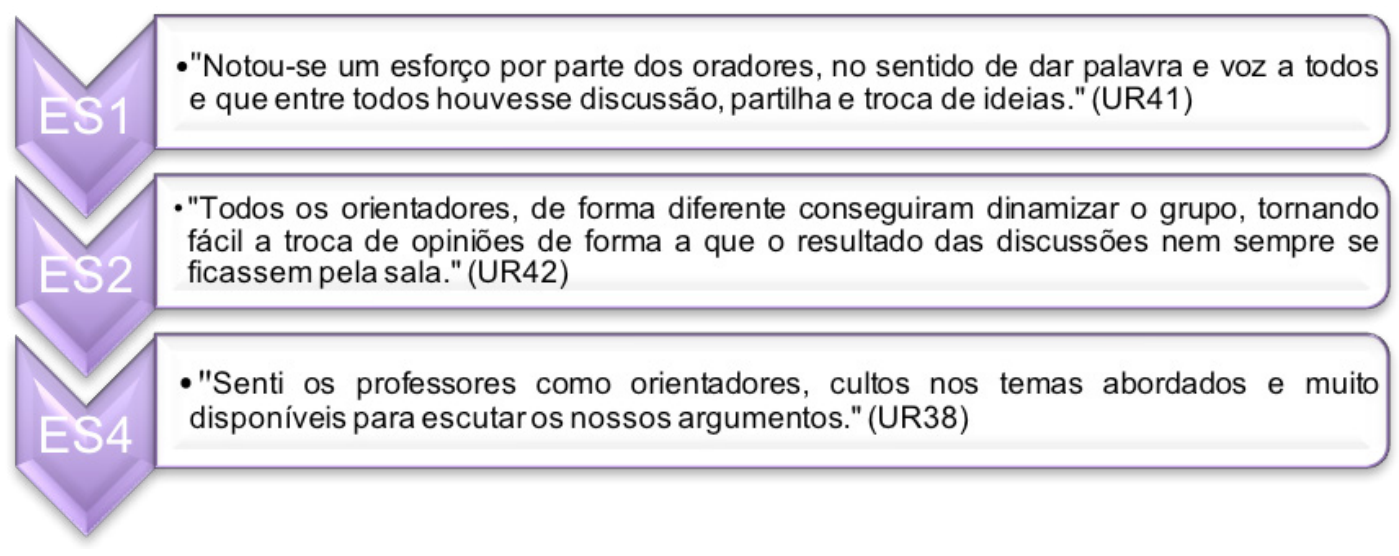

Figura 3: Presença Docente (Fonte: Elaborado pelos autores)

Como podemos ver nas três unidades de registo exemplificativas os estudantes, referem que a presença dos docentes foi muito importante, porque estes orientaram as discussões, lançando questões que convidaram à reflexão e ao trabalho colaborativo. Para além disso destacaram, também, que os professores criaram um ambiente propício à troca de opiniões, sendo que na opinião do estudante -ES2- estas discussões foram expandidas para fora da sala de projeção dos filmes. Houve como que um ampliar da sala para os ambientes mais fechados das celas da prisão. Ainda de destacar a ideia sublinhada pelos estudantes -ES2- e -ES4- que se referem aos professores como "orientadores" e facilitadores do processo de aquisição de conhecimento, respeitando e ouvindo sempre as ideias e os argumentos do grupo. Estes são testemunhos interessantes que confirmam uma das linhas de força do modelo: a Experiência Educacional de Cariz Humanista, onde os estudantes se assumem, por um lado, como indivíduos ativo, construtores do seu conhecimento, empenhando-se e comprometendo-se com o seu processo de aprendizagem e integrados numa comunidade, e os professores, se assumem como moderadores que orientam a experiência educacional e que fomentam uma interação humana positiva. 
No mesmo sentido os estudantes -ES5-, -E10- e Es13- sublinharam a mesma ideia, referindo que:

ES5- "Sem dúvida que a capacidade dos professores, em orientar cada sessão, apresentando bons argumentos, facilitou a troca de opiniões entre o grupo, onde todos interagiram de uma forma positiva." (UR45)

ES10- “0s vários professores foram sempre muito participativos e incentivaram a discussão o que é muito importante para aprender ideias novas. (UR50)

ES13- "0s professores estiveram sempre bem, foram esclarecedores sempre que fizeram intervenções, como ao mesmo tempo lançavam dicas para alimentar as discussões... Foi positivo. (UR53)

Este papel de professor-orientador, de professor-facilitador, de professor -mediador, relaciona-se com uma nova cultura de aprendizagem intrínseco ao modelo proposto, que pressupõe que os professores, mais do que transmitir ou ditar informações, devem promover nos seus estudantes, competências de procura, seleção e interpretação da informação disponível, assumindo-se como mediadores e facilitadores (Salmon, 2003).

Outros estudantes têm testemunhos idênticos, reforçando estas ideias:

ES6 "Gostei da "agressividade" com que os problemas eram colocados: abertura, sem equívocos, ambiguidades e sem tabus..." (UR46)

ES8- "As opiniões eram diferentes e colidiam na mesma interpretação. Uma vez a Doutora X não concordou e interpelou-me. Nada que não fosse bem discutido e resolvido!" (UR48)

ES9- “0 professor levantou questões importantes, provocou, falou em tabus e conduziu as discussões com uma postura assertiva e algumas vezes deixou-me em "looping" acerca de certas perguntas." (UR49) 
Todas estas perceções dos estudantes revelam que uma das maiores potencialidades desta estratégia, com recurso ao cinema, e do modelo prende-se com a interatividade e interação, que se pode estabelecer entre os diferentes participantes. E neste processo de interação, percebe-se que o professor é o responsável por identificar os conhecimentos relevantes, propor experiências que levem ao discurso crítico e à reflexão, diagnosticar e avaliar os resultados de aprendizagem (Garrison \& Anderson, 2005).

Isso é notório quando os estudantes, como o -ES6- ou -ES9-, se referem à abertura e à colocação de ideias sem tabus, e como a postura assertiva de um professor o deixou em "looping", como diria Jean Piaget em conflito cognitivo, como foi muito percetível no filme 300, do realizador Zack Snyder, aquando da discussão de temas como a sexualidade ou a educação na Grécia Antiga, e como eram encaradas de forma distinta em Esparta e Atenas.

\section{Discussão}

Como foi referido na parte introdutória deste texto, os indivíduos em situação de reclusão têm o direito a uma educação de qualidade e diversificada sendo que esta deve ser adequada às exigências desta nova "Sociedade do Conhecimento". A adoção de modelos de formação, no quadro da concretização do Processo de Bolonha em Portugal, que consagrou a transição de um sistema de ensino baseado na ideia da transmissão de conhecimentos para um sistema baseado no desenvolvimento de competências (Decreto-Lei n. ${ }^{0}$ 74/2006, de 24 de março ${ }^{1}$ ), assim como a relação entre a formação que é dada no interior dos estabelecimentos prisionais e no sistema educacional, assumem-se como fundamentais para alcançar esta educação de qualidade (Council of Europe Recommendation on Education in Prison, 2011).

E foi, pois, com base nestes pressupostos, e tendo em conta as potencialidades do cinema, mais concretamente do cinema de ficção científica, que decidimos desenvolver este programa de Educação para a Cidadania assente num modelo pedagógico centrado na "desconstrução" de imagens em movimento. 
0 resultado do nosso estudo, tendo em conta estas perceções, revelam que, efetivamente, este modelo pedagógico pode ter um efeito muito positivo na criação de comunidades de aprendizagem, com um impacto a nível do desenvolvimento de competências como a colaboração, comunicação, a criatividade e o espírito, competências consideradas fundamentais para o cidadão do século 21.

Através da análise das perceções dos estudantes nas dimensões das Presenças Cognitiva e Social pudemos concluir que a estratégia pedagógica com o recurso ao cinema de ficção científica permitiu criar um ambiente favorável e promotor de um processo de pensamento crítico. Um ambiente colaborativo, onde o estudante assumiu o dever de dar sentido à sua experiência educacional, através da negociação de significados com o grupo e onde foi partilhada informação e conhecimento, com autonomia e criatividade.

No que diz respeito à dimensão da Presença Docente concluímos que os estudantes consideram que este foi um elemento muito importante no processo, na medida em que cabe ao professor a tarefa de implementar e desenvolver a comunidade e orientar a aprendizagem dos seus membros, criando discussões estimulantes, e como destacaram alguns estudantes sem tabus, nem preconceitos e com "loopings" de pensamento constantes, facilitando, assim, a construção de um pensamento crítico.

Podemos, pois, afirmar, com base nas perceções destes estudantes, que esta estratégia, assente na visualização de filmes (de ficção científica, neste caso), ancorada por um modelo pedagógico construtivista, possui um enorme potencial na formação e desenvolvimento de comunidades de aprendizagem, mesmo em ambientes de reclusão.

Terminamos, referindo que o cinema permite, efetivamente, equacionar o processo educativo de forma diferente. No entanto, a mudança não deve ser vista só do ponto de vista pedagógico, mas também em termos culturais, pois obriga a repensar os papéis dos professores e dos estudantes e a relação existente entre eles, para além das implicações que devem ser concretizadas no plano da reconfiguração dos ambientes de aprendizagem. 


\section{Referências bibliográficas}

Bardin L. (1977). L'analyse de contenu, Paris, PUF.

Bukataman, S. (1997). Blade Runner. London: British Film Institute.

Council of Europe (2011). Recommendation of the Committee of Ministers to member states on the European Prison Rules. Disponivel em: https://wcd.coe. int/ViewDoc.jsp?id=955747.

Comissão Europeia (2005). eEurope - uma sociedade da informação para todos. Bruxelas: Serviço de Publicações da Comissão Europeia. Retrieved April 17, 2017: http://europa.eu/legislation_summaries/information_society/124221_ pt.htm

Comité de Ministros do Conselho da Europa (1989). Recomendação (89) 12, de 13 de outubro.

Fresquet, A. (2013). Cinema e Educação. Reflexões e experiências com professores e estudantes de educação básica, dentro e "fora" da escola. Belo Horizonte: Autêntica.

Featherstone, M. \& Burrows, R. (1995). Cyberspace, Cyberbodies, Cyberpunk: Cultures of Technological Embodiment. London: Sage Publications.

García Amilburu, M. \& Lenderos Cervantes, B. (2011). Teoría y práctica del análisis pedagógico del cine. Madrid: UNED.

Garrison, D. \& Anderson, T. (2005). El e-learning en el siglo XXI. Investigación e práctica. Barcelona: 0ctaedro.

Haraway, D. (1991). Simians, Cyborgs, and Women. London: Free Association Press.

Kuhn, A. (1990). Alien Zone: Cultural Theory and Contemporary Science Fiction Cinema. London, New York: Verso.

Kuhn, A. (1999). Alien Zone II: The Spaces of Science Fiction. London, New York: Verso

James, E. (1994). Science Fiction in the Twentieth Century. 0xford/New York: 0xford University Press.

Miles, M. \& Huberman, M. (1994). Drawing valid meaning from qualitative data: toward a shared craft. Educational Researcher, 13, 20-30.

Moreira, J. A. \& Almeida, A.C. (2011). How reliable and consistent is our learning community of inquiry? Psychometric qualities of the community of inquiry survey instrument applied to a sample of higher education Portuguese 
students. EduLearn 2011. International Conference on Education and New Learning Technologies 4th-6th July, 2011 - Barcelona (Spain)

Moreira, J. A. \& Monteiro, A. (2010). 0 Trabalho Pedagógico em Cenários Presenciais e Virtuais no Ensino Superior. Educação, Formação \& Tecnologias, 3(2), 82-94. Roberts, A. (2000). Science Fiction. London, New York: Routledge.

Salmon. G. (2000). E-Moderating. The Key to Teaching and Learning Online. London: Kogan Page

Salmon, G. (2003). E-tivities: the key to teaching and learning online. Londres: Routledge.

Spiro, R., Vispoel, W., Schmitz, J., Samarapungavan, A. \& Boerger, A. (1987). Knowledge Aquisition for Application: Cognitive Flexibility and Transfer in Complex Content Domains, In B. Britton \& C. Glynn C. (eds.), Executive Control in Processes in Reading (p. 177-199), New Jersey: Lawrence Erlbaum Associates. Spiro, R., Coulson, R., Feltovich, P. \& Anderson, D. (1988). Cognitive flexibility: Advanced knowledge acquisition ill-structured domains. Proc. of the Tenth Annual Conference of Cognitive Science Society. Hillsdale: Erlbaum, 375-383. Telotte, J. P. (2001). Science Fiction Film. Cambridge: Cambridge University Press. UNESCO (1998). Declaração mundial sobre educação para todos. Disponível em URL: http://unesdoc.unesco.org/images/0008/000862/086291por.pdf.

Vala, J. A. (1986). Análise de conteúdo. In A. Silva \& J. Pinto (eds.), Metodologia das Ciências Sociais. Porto: Edições afrontamento.

Wang, F. \& Hannafin, M. J. (2005). Design-based research and technology-enhanced learning environments. Educational Technology Research and Development, $53(4), 5-23$.

\section{Notas}

[1] Diário da República, n. ${ }^{\circ}$ 60/ 2006, Série I-A 2006-03-24.

\section{(@) $(1) \Theta$}

Esta obra está bajo una licencia de Creative Commons Reconocimiento-NoComercial 4.0 Internacional. 